\title{
Poverty, wealth inequality, and health among older adults in rural Cambodia
}

Zachary Zimmer

Follow this and additional works at: https://knowledgecommons.popcouncil.org/departments_sbsr-pgy

Part of the Demography, Population, and Ecology Commons, Family, Life Course, and Society Commons, Gerontology Commons, Inequality and Stratification Commons, International Public Health Commons, Medicine and Health Commons, and the Rural Sociology Commons How does access to this work benefit you? Let us know!

\section{Recommended Citation}

Zimmer, Zachary. 2006. "Poverty, wealth inequality, and health among older adults in rural Cambodia," Policy Research Division Working Paper no. 217. New York: Population Council. 


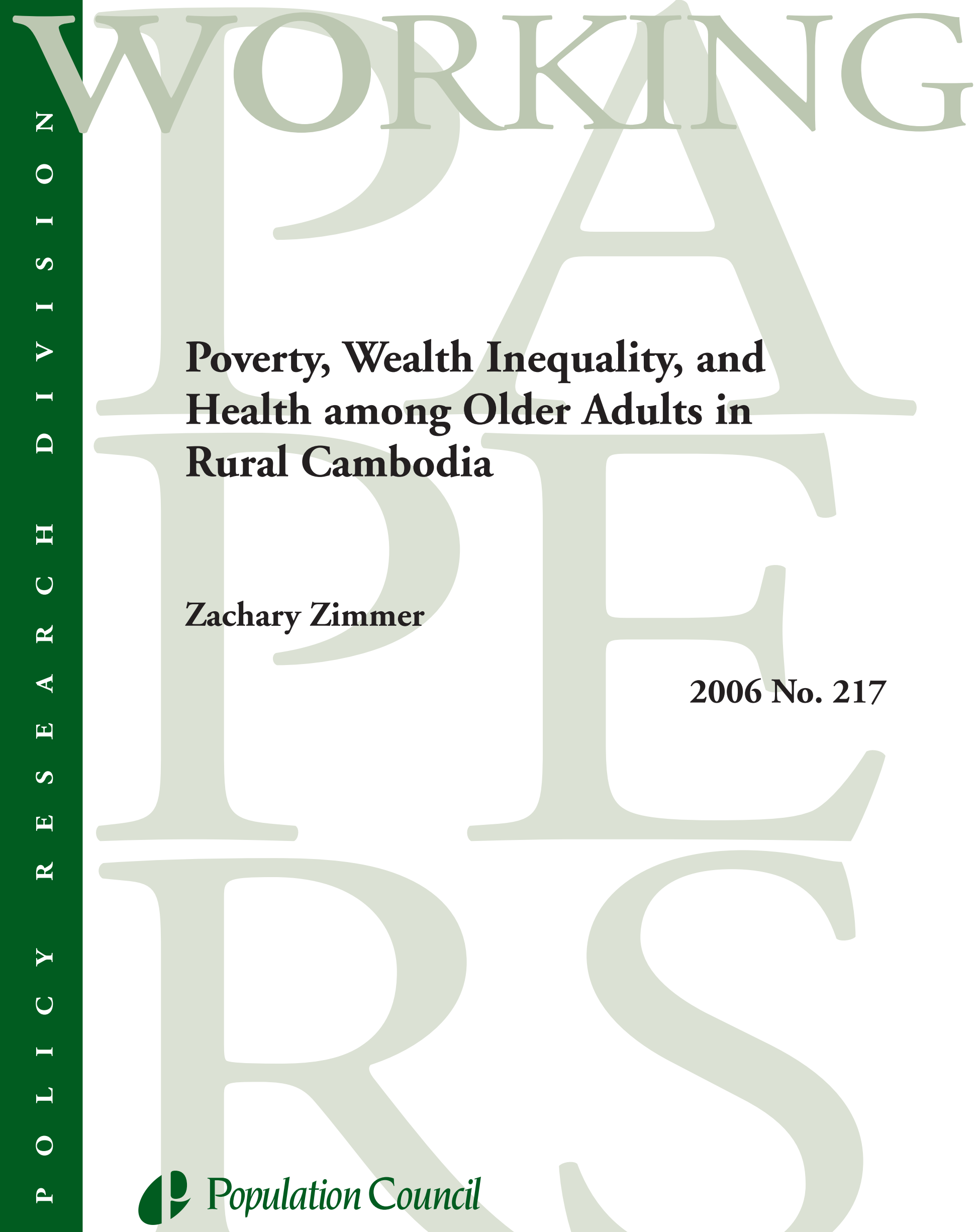




\section{(1) Population Council}

One Dag Hammarskjold Plaza

New York, New York 10017 USA

www.popcouncil.org

pubinfo@popcouncil.org

This material may not be reproduced without written permission from the author. For a list of Policy Research Division Working Papers, including those that are currently available for downloading in PDF format, see www.popcouncil.org/publications/wp/prd/rdwplist.html.

ISSN: $1554-8538$

(C) 2006 The Population Council, Inc. 


\title{
Poverty, Wealth Inequality, and Health among Older Adults in Rural Cambodia
}

\author{
Zachary Zimmer
}

Zachary Zimmer is Senior Scholar, Institute of Public and International Affairs, and Professor, Department of Sociology, University of Utah, Salt Lake City. 


\begin{abstract}
This paper examines the distribution of household wealth and tests whether associations exist between wealth inequality and health outcomes among older adults living in one of the world's poorest regions, rural Cambodia. The 2004 Survey of the Elderly in Cambodia, the first probability sample survey of the country's elderly population, is employed. Health is conceptualized as having multiple components and is operationalized using a disablement process. As such, associations are shown for four types of health indicators - symptomatic conditions, sensory impairments, physical functioning limitations, and disabilities related to activities of daily living. Wealth inequality is determined using a Demographic and Health Survey index, which operationalizes wealth as the ownership of a variety of assets. Results confirm difficult economic conditions among most elderly in rural Cambodia. The lowest wealth quartile lives in households that own virtually nothing, while the next two quartiles are only slightly better off. Nevertheless, logistic regression that adjusts for age, sex, and several other covariates indicates heterogeneity in health exists across quartiles that otherwise appear qualitatively similar. Those in the bottom quartile of wealth report more health problems than those in the second and higher quartiles. An exception occurs using disability as a health outcome since those in the lowest and highest quartiles have similar probabilities of reporting limitations in activities of daily living. It is difficult to determine the factors behind the relationship between wealth and well-being, particularly given the cross-sectional nature of the data, although the final section speculates on causal directions. This study suggests there is some validity to generalizing the relationship between wealth inequality and health to extremely poor populations and that a very small difference in wealth makes a relatively large difference in regard to the association with health among those living in impoverished surroundings.
\end{abstract}


Evidence confirming that economic inequality has implications for predicting adult health status dates back decades. Corroboration of an association between various measures of economic well-being and health has been found in Europe, the United States, and elsewhere in the developed world (e.g., Antonovsky 1967; Fox 1989; Huisman, Kunst, and Mackenbach 2003; Kadushin 1964; Kitagawa and Hauser 1973; Mackenbach et al. 1997; von dem Knesebeck et al. 2003). Receiving particularly close scrutiny in recent times has been the influence of earned income, and an advantage for higher earners has been a persistent finding (Ecob and Smith 1999; Gornick et al. 1996; McDonough et al. 1997; Smith 1999; Sorlie, Backlund, and Keller 1995; Wilkinson 1986; Zimmer and House 2003). Moreover, measures of economic status that indicate long-term well-being, such as accumulated liquid assets, bank savings, and home ownership, have occasionally been shown to be as valuable for predicting health outcomes as is current earned income (Lynch, Kaplan, and Shema 1997; Robert and House 1996; von dem Knesebeck et al. 2003; Zimmer and Kwong 2004).

Researchers are increasingly asking whether basic associations that have implications for health can be generalized to older populations. The focus on older persons is of particular consequence given the population aging that is occurring across the globe and the subsequent increase in the proportion of health care costs being consumed by the elderly (Mayhew 1999; Zimmer 2006b). In developed countries, studies have indicated that the impact of income inequality extends to older people (Backlund, Sorlie, and Johnson 1996; Berkman and Gurland 1998; Grundy and Sloggett 2002; Huisman, Kunst, and Mackenbach 2003 Matthews, Jagger, and Hancock 2006; von dem Knesebeck et al. 2003). The influence of long-term measures of wealth on health, as opposed to the effect of current earned income, is particularly critical, since older persons are often retired from work and may depend on an accumulation of assets or on assistance from others for their material well-being.

Most previous research examining the link between economic inequality and health among older adults has been conducted in developed countries. A lesser number of studies have been conducted in rapidly developing or middle-income countries, such as China and others in East Asia (e.g., Beydoun and Popkin 2005). The connections between poverty and health have been assessed to a limited extent in the developed world (Backlund, Sorlie, and Johnson 1996; Haan, Kaplan, and Camacho 1987; Menchik 1983). The demographic and epidemiological literature has examined issues related to poverty and infant, child, and maternal mortality in developing countries (Hobcraft, McDonald, and Rutstein 1984; Houweling et al. 2005; Montgomery and Hewett 2005). But it appears that there has been no test of the association between economic inequality and health among older adults within an extremely poor society, despite the fact that many of the world's elderly populations live in such environments.

Affirming associations between economic inequality and health within settings of extreme poverty, where there is less variation in economic well-being than is typical in better-off societies, and where valid indicators of economic well-being may differ from those traditionally considered, would go a long way toward establishing the existence of a persistent, robust, and universally applicable generalization. The current study takes place in such a setting: rural Cambodia. The modern history of Cambodia is replete with periods of war, violence, and genocide, which peaked between 1975 and 1979 during the devastating rule of Pol Pot and the Khmer Rouge (Heuveline 1998; Kiernan 1996). Although Cambodia was a poor country before 
this period, the disorder that occurred during and immediately after the Khmer Rouge ensured that many of its inhabitants remained in extreme poverty. Today, the United Nations classifies Cambodia as one of the world's least developed countries, and it ranks low on the Human Development Index with over three-fourths of the population living on less than \$2 a day (Ministry of Planning 2003). It has low levels of literacy (74 percent of the population is illiterate) and high levels of overall and infant mortality (life expectancy at birth of 56 years; 95 infant deaths per 1,000 births) (Population Reference Bureau 2005). Poverty is especially pervasive in rural areas. An earlier study using the same data as in the current study indicated that less than 9 percent of older adults in rural areas live in a household with a telephone, less than 2 percent in a household with a car, and less than 1 percent in a household with a refrigerator (Knodel et al. 2006). The same report showed only 20 percent of older Cambodians in rural areas believe they have enough money each month to meet their expenses.

If the link between economic inequality and health is universal across societies and cultures, as is sometimes suggested (National Research Council 2001), one would expect health differentials to appear even at the very bottom of a global wealth continuum. Therefore, a starting hypothesis may be that economically based gradients in health exist among older adults in rural Cambodia. Nonetheless, there are reasonable bases for suspecting the contrary. Research has shown that the health status of older Cambodians is generally poor, even in comparison to older adults in other countries in the region, hence there may be little variation in health (Zimmer 2006a). Health care resources throughout rural Cambodia are underdeveloped and underfunded (Annear 1998). Although economic resources may allow for the purchase of health care in more prosperous urban surroundings, availability and use are minimal for almost all rural Cambodians, regardless of individual resources. Furthermore, research findings from middle-income and rapidly developing countries have been mixed. Conflicting results, for instance, have been found in those Asian settings where the association between economic status and health has occasionally been tested (Anson and Sun 2003; Beyodoun and Popkin 2005; Chiu et al. 2005; Kaneda, Zimmer, and Tang 2005; Zimmer and Amornsirisomboon 2001; Zimmer et al. 2004).

\section{METHODS AND INDICATORS}

\section{Data}

Data come from the 2004 Survey of the Elderly in Cambodia, the first probability sample survey completed in the country specifically geared to older adults. The survey involved face-toface interviews with 1,273 individuals aged 60 and older between April and October 2004. It took place in the homes of older adults and was completed in approximately one hour. A range of topics was covered, including demographic characteristics, health, socioeconomic status, and other factors pertinent to the well-being of the elderly. Respondents came from Cambodia's six most populous provinces, which together contain more than half of the country's population: Battambang, Kampong Cham, Kandal, Phnom Penh, Prey Veng, and Takeo. A multi-stage sampling design involved a proportionate-to-size systematic selection of villages within the six provinces, followed by a random selection of households containing at least one older adult, and finally a selection of one older adult within each household. A weighting scheme was established so that results are representative of the older population within the six provinces. Analysis 
performed on the weighted sample affirmed that it is representative based on comparisons with other data sources, such as the 1998 census and the 2004 intercensal survey. Results below refer to the weighted sample. Details about the survey, data, sampling, and weighting are available in Knodel et al. (2005). Recent publications that employ this dataset include Zimmer (2006a) and Zimmer et al. (2006).

The current study is limited to 1,011 respondents in rural areas, or about 90 percent of the total sample. Urban residents were eliminated since indicators of economic status and the conceptualization of poverty differ widely between urban and rural areas. Of the questionnaires completed by the current sample, 34, or about 3 percent, were assisted by a proxy. Proxies were used in cases where the older adult was incapable of responding to items because of cognitive or hearing impairments. Proxies were individuals closely associated with the older adult, such as a spouse or a caretaking adult child. An earlier version of the analysis removed proxy responses, but results did not substantially differ from those presented here.

Table 1 presents descriptive information about the sample. Females make up more than half of the sample, as do those between ages 60 and 69. Most of the men are married while most women are widowed. The sample is predominantly of Khmer ethnicity and Buddhist. Generally, respondents are uneducated, although women are much more likely to have had no schooling. About half of men and a third of women reported that they worked at some point within the last year, mainly in agriculture. About 75 percent of women and 84 percent of men live with at least one of their grown children. Almost half the sample lives in households with six or more people. Women have a substantially higher probability of living either alone or in two-person households.

\section{Health status}

Indicators of health status in the 2004 survey relate to domains within a "disablement process" conceptualized by Verbrugge and Jette (1994), which itself borrows from earlier disablement conceptualizations by the World Health Organization (1980) and Nagi (1979). The domains are pathology, sensory impairment, functional limitation, and disability. Each pertains to particular sets of health issues. They provide a well-recognized way of organizing and conceptualizing the multiple components of health and the health problems typically faced by older adults regardless of the country or culture from which they come. The study will examine the extent to which economic inequalities are related to health inequalities within each domain.

Pathology refers to physiological abnormalities that can be medically diagnosed and labeled as specific diseases. When constructing the survey instrument, it was presumed that asking questions about diagnosable diseases would be unproductive given that doctor visits are rare for this population and specific diseases often go undiagnosed and unrecognized. Instead, respondents were read a list of easily recognizable health symptoms thought to relate to specific diseases and were asked whether they experienced the symptom in the past month. Pathological disorders can lead to impairments, which refer to general bodily dysfunctions. Respondents were asked specifically about two sensory impairments: eyesight and hearing capacity. Impairments can lead to functional limitations, which are difficulties conducting basic physical movements. Respondents were read a list of these and asked whether, on their own, they have difficulty 
conducting the movement and, if so, the degree of difficulty (a little, a lot, or cannot conduct the movement). Finally, functional limitations can lead to disabilities, the inability to perform tasks necessary for daily living. More so than the previously described measures, disabilities can be influenced by environmental factors and social customs (Freedman and Martin 1998; Verbrugge and Jette 1994). For instance, having difficulty bathing depends upon the type of bathing facility available and the assistance one receives in conducting the task. Hence, difficulty bathing may be partly a result of functional limitation and partly a result of one's social and physical environment. The survey included four disability items commonly referred to as activities of daily living, which are tasks necessary for daily self-maintenance (Katz et al. 1963). As with functional limitations, respondents were asked whether they experienced difficulty and, if so, the degree of difficulty.

A dichotomous summary measure was constructed for each of the four domains. For symptoms, only 1 percent of respondents reported none, while the mean and median number reported was six. Therefore, a dichotomous summary measure was constructed indicating whether an individual reported less than six or six or more symptoms. For the other three domains, the summary measure indicates whether one or more problems were reported. A sensory impairment includes reporting a problem seeing or hearing or both. A functional limitation means having a lot of difficulty with, or being unable to perform, one or more tasks. A disability means having difficulty with at least one task. Table 2 shows the percent reporting health problems for the full sample and by age and sex. Fifty-seven percent reported six or more symptoms, 70 percent reported a sensory impairment, 53 percent a functional limitation, and 23 percent a disability. The percent reporting health problems increased substantially by age. Women were more likely to report health symptoms, functional limitation, and disability, but there is little difference in sensory impairment by sex.

\section{Household wealth}

Household wealth has a number of advantages as an indicator of economic well-being for older adults and as a means of examining wealth inequalities, particularly within this population. First, it is a more permanent indicator of well-being than is income or consumption (Rutstein and Johnson 2004). This is particularly the case with the elderly, who are often retired and thus do not earn current income. Second, in Cambodia, as in other developing countries, older people tend to rely on family members for their material survival. Therefore, the economic status of the household is a more pertinent indicator of material well-being than personal income or wealth. Third, household wealth is fairly easily measured in surveys through questions about assets.

The current study employs a measure based on a Demographic and Health Survey wealth index conceptualized by Rutstein and Johnson (2004). The index is based on the notion that wealth is an underlying and unobservable measure relating to relative economic position within a social hierarchy. The assumption is that within any population there will be households that are relatively better off and others relatively worse off, and therefore household wealth is a comparative measure. The position of a particular household within the hierarchy is determined by the use of variables that indicate whether the household owns or contains a number of assets

or structural components. This study considers information regarding whether the household 
contains the following: a radio, television, modern toilet (one that can be flushed), jewelry, motorcycle, modern floor (finished wood, vinyl, asphalt, ceramic, marble, or cement), telephone, fan, car, and refrigerator.

Construction of the index follows from Filmer and Pritchett (2001). Each indicator is dichotomized as 1 if the asset is present and 0 otherwise. The contribution of each indicator to the index is determined by a principal component analysis that assumes a single factor is derived from the series of assets. The procedure involves standardizing the indicator, determining its factor loading through principal component analysis, multiplying the loading by the standardized score, and summing the products. Each individual in the sample then has a wealth score that has a mean of 0 and a standard deviation of 1 , with the score being the result of assigning weights to each asset. Scores are ranked from top to bottom and, for the current study, are divided into quartiles as closely as possible. Given a sample size of about 1,000, some 250 respondents will fall within each quartile of the household wealth index. The numbers within quartiles are not exactly the same owing to a good degree of heaping around ownership of certain items. For instance, 131 respondents, or about 13 percent of the sample, live in households that have a radio and television but no other assets. Findings below show more specific information about the wealth index and the derived quartiles.

\section{Analysis}

The analysis first examines poverty and household wealth by looking at a number of characteristics of older persons within wealth quartiles. For instance, the number and type of assets owned by the households in which older adults live and various demographic characteristics of older adults are compared across quartiles. Next, logistic regression equations are employed to predict the odds of various health problems (six or more symptoms, sensory impairment, functional limitations, and disability) across wealth quartiles, using the lowest quartile as the comparison category. The first set of equations adjusts probabilities by age (measured categorically as 60 to 64,65 to 69,70 to 74 , and 75 and older, with the youngest age group being the comparison category) and sex (with male as the comparison category). The second set of equations adds additional controls to determine the robustness of initial associations. The $-2 \mathrm{X} \log$-likelihood (LL) statistic, which is distributed as $\chi^{2}$, is employed as an estimate of whether wealth overall is significantly associated with the reporting of health problems. Robust standard errors that account for sample design by considering clustering by village are used to determine statistical significance of individual variables. Because there is a starting hypothesis of an inverse association between wealth and reporting of health problems, and because the sample size is relatively small, two-tailed significance levels up to $\mathrm{p}<.10$ are noted. Descriptive statistics were analyzed using SPSS 14.0, and multivariate logistic regressions were conducted using STATA 9.2.

\section{FINDINGS}

\section{Poverty among older adults in rural Cambodia}

Table 3 presents information about wealth and poverty in three panels. Panel A describes the distribution of household assets owned, out of the ten that were considered, across wealth 
quartiles. Panel B shows specific assets owned. Panel C presents selected demographic characteristics of older adults across wealth quartiles.

Panel A indicates that individuals who score low on the wealth index tend to live in households that have few or no assets, while those who score high live in households with more assets. The mean number of assets owned is only 0.45 for those in the lowest quartile, rising to 5.57 for the highest quartile. For the entire sample, the mean number is only 2.44; on balance, therefore, the households in the sample can be described as having very little wealth.

Perhaps more telling are the median and range of assets, the latter shown by presenting the $10^{\text {th }}$ and $90^{\text {th }}$ percentiles for distributions of number of assets. The median number of assets owned for those in the lowest quartile is 0 , so at least half of the 289 individuals within this group do not have any of the items that constitute the wealth index. In addition, the $10^{\text {th }}-90^{\text {th }}$ percentile range is 0 to 1 , indicating that individuals in this quartile own either no assets or only one. Although in a relative sense those in the second quartile have greater wealth, the qualitative increase is trivial. The median number of assets owned for the second quartile is 2 and the range is 1 to 2 . There appears to be a qualitative increase in wealth only in the highest quartile, where the median is 5 and the range is 4 to 8 . Thus, with the possible exception of some of those in the highest quartile, older adults in rural Cambodia have a very low economic standard of living.

Panel B shows that about two-thirds of the total sample own a radio. However, only about 45 percent of those in the lowest quartile own a radio, and no one in the lowest quartile owns any asset other than a radio. This result is a function of the way in which the wealth index was constructed. Therefore, those in the lowest quartile are individuals living in households that have none of the ten assets or have only a radio. A large proportion of this population lives in very primitive housing conditions, subsists only on what they grow, and owns only a few essential items such as clothes and some cookware.

The elderly in the second quartile are not much better off. The small gain in wealth typically relates to ownership of a television. A majority of households in the second quartile also own a radio. Households occupying the third quartile own a greater mix of assets. Most own both a radio and television, while others have a modern toilet, jewelry, and a motorcycle (moped). Yet, a modern floor is still rare for this group, suggesting that even those in the third quartile live in primitive housing. There is an appreciable step-up in asset ownership in the highest quartile. Modern toilets and floors are more common, suggesting generally better housing. Many also own jewelry, a motorcycle, fan, and telephone.

Panel $\mathrm{C}$ more broadly examines the characteristics of the population within wealth quartiles. Females and those who are married are least likely to occupy the third quartile, but sex and marital status distributions do not differ greatly across quartiles. There is more variation in the percent with schooling. As expected, the elderly in the two lower quartiles are much less likely to have had schooling. Those in the highest quartile are much more likely to have worked in the past year. The fraction living with a grown child increases steadily from about 65 percent to 90 percent between the lowest and highest wealth quartile, and the mean household size increases from 4.2 to 6.4. Clearly, living with children and with a greater number of people leads to some accumulation of assets, which is reflected in the measure of wealth. In sum, those in the highest quartile tend to be better-educated nonagricultural workers living in large households; 
those in the lowest quartile tend to be uneducated agricultural workers living in small households.

\section{Wealth inequality and health}

The first four columns in Table 4, labeled Model 1, show the relationship between wealth and health, adjusting for age and sex. Looking at this model, the $-2 \mathrm{X} \mathrm{LL}$ indicates that wealth is significantly associated with each of the summary health measures. Despite the qualitatively minor difference in wealth between the lowest and the second quartile, for all summary measures those in the second quartile are less likely to report health problems. The decline is statistically significant at $\mathrm{p}<.05$ for functional limitation and disability and at $\mathrm{p}<.10$ for sensory impairment. The decline in the odds of reporting health symptoms is not significant between the lowest and second quartile in Model 1, but the magnitude of decline is fairly steep nonetheless. There is an inverse association between wealth and health problems that is relatively linear for health symptoms and sensory impairments, that is, each gradient of wealth is associated with lower odds of reporting problems. There is a clear decline in the odds of reporting functional limitation with increasing wealth, although the association flattens at the upper two quartiles. Disability presents an anomaly. The association is more or less U-shaped. Although those in the second quartile are less likely to be disabled than those in the lowest quartile, there is no significant difference in disability between the lowest, third, and highest quartiles.

The effects of age and sex are as expected. Older age is related to higher odds of reporting health problems, and, except for sensory impairment, women are more likely than men to have health problems.

Although, given the cross-sectional nature of the survey data, it is difficult to specify the factors determining the associations, it is possible to ascertain some of the possible explanations by adjusting for additional demographic characteristics. One reason why associations between wealth on the one hand and functional limitation and disability on the other are not totally linear may be that those in the highest quartile are the least likely to have worked most of their lives in agriculture, and the physical labor involved in agriculture may confer some benefit to physical functioning (Zeng et al. 2001). Therefore, the analysis considers whether respondents have worked in agriculture for most of their lives. Second, it is possible that older adults who develop health problems, particularly problems that limit ability to carry out daily functions, have a greater need for obtaining care and are therefore more likely to live with their offspring or others who can provide physical assistance. Indeed, this is a common expectation in much of the developing world, where social security and other means of formal support are not readily available (Bongaarts and Zimmer 2002; Hermalin, Ofstedal, and Shih 2003; Martin 1988). In turn, as was seen above, the wealthier quartiles are made up of larger households. Therefore, household size may explain some of the anomalous association with disability. (Living with offspring is another variable to consider. However, it is highly correlated with, and provides results similar to, household size.) Third, although the direction of causality cannot be fully tested using cross-sectional data, one likely explanation for the association between wealth and well-being is that healthier individuals are able to continue working to an older age. Work, in

turn, brings income, which leads to an increase in wealth. This may explain why those in the 
second quartile are healthier than those in the lowest. Both quartiles contain mostly people working in agriculture, but the second quartile may have healthier individuals who continue working. Their continued income allows them to assist their household in the purchase of assets. Therefore, the analysis considers whether individuals report that they worked within the last year. Finally, additional adjustments were made for marital status and having formal schooling, since these two factors are thought to be related to health.

These additional controls are presented in Model 2. Rather than explaining away associations seen in Model 1, the additional controls appear to make some more robust. For instance, in predicting health symptoms, the difference in the association between the first and second quartile is now significant. The decline in the odds of reporting a functional limitation is steeper for the first three quartiles and then levels off more definitively for the last. For all health outcomes, those in the second and third quartiles report significantly fewer health problems than those in the lowest. The association with disability remains U-shaped.

Marital status is unrelated to health. Schooling is generally unrelated except for its influence on functional limitation, which is not in the expected direction. The lack of importance of education for health when controlling for wealth was unanticipated but not without precedent in developing countries (Liang et al. 2000; Liang, Liu, and Gu 2001; Zimmer et al. 2004; Zimmer and Kwong 2004). Contrary to expectations, those in agriculture are not healthier than others; indeed, they are more likely to report health symptoms and functional limitations. Also contrary to expectations, household size is generally unrelated to health, with the exception that those with health symptoms are more likely to be living in larger households. Equations controlling for each variable separately (including living with offspring) were examined (results not shown). These results are very similar to those shown in Model 2, which control for variables simultaneously.

In other additional analyses, not presented here, the association was tested for each individual health problem that contributes to the summary measures of health. The association with wealth is linear or nearly linear for most of the health symptoms, with some variation across specific symptoms. The consistency of results across individual measures implies that the summary measures presented here represent the general patterns very well. Other analyses also indicated that creating dichotomous summary measures using different cut points results in similar results.

A more intuitive look at the association between wealth and health is offered in Figure 1. Here, coefficients from Model 2 are used to determine the predicted probability of reporting a health problem. This was done by holding constant all variables, except wealth, and deriving a mean sample probability across all cases. Results can be interpreted as the probability that an otherwise average respondent, or a respondent who scores at the mean on all other variables, would report health problems. The figure emphasizes that those in the lowest quartile have a consistently higher probability of reporting health problems than do those in the second quartile. The decline in the probability of reporting sensory impairment or health symptoms is linear across quartiles, while the probability of reporting functional limitation levels off at the higher quartiles. In contrast, there is a U-shaped association with disability, which is not explained by control variables in Model 2. 


\section{CONCLUSION}

An abundance of evidence from developed countries links economic well-being and health, while additional studies show that the association holds generally among older adults. The nature of this link provides critical information for reducing health inequalities and, in view of trends in population aging, for managing health care costs. The current study, however, takes place in an extreme environment, rural Cambodia, where older people not only are poor by any global standard, but have also endured years of civil strife and unfavorable living conditions, such as a lack of adequate health care and otherwise weak infrastructure. Because research on health determinants among the elderly in economically deprived regions is scarce, little is known about how acute lifetime deprivation affects the aging process and whether relationships thought to be universal are in fact applicable to these environments.

The test of the relationship between wealth and health conducted above suggested greater heterogeneity than might have been expected. The following are some viable conclusions. 1) Differentiation in health is found across gradients of wealth within this population. Indeed, a robust disparity in health exists between those in the lowest quartile and those in the second quartile. Therefore, relative inequality seems to matter. 2) Changes in the probability of reporting health symptoms and sensory impairments are linear with increasing wealth quartiles. Each increase in wealth quartile is related to a noticeably lower probability of reporting these health problems. 3) There is a decline in the probability of reporting a functional limitation with increasing wealth, but a leveling off occurs at the two highest quartiles. 4) The relationship between wealth and disability is anomalous. The association is U-shaped, and the net effect is not as statistically robust.

The survey data used here are cross-sectional, making it difficult to assess causal mechanisms behind the associations. At best, this study presents associations but is unable to pinpoint a causal sequence. Nonetheless, some speculation is possible based on the results shown here and on earlier theoretical literature. One possibility is that associations run from health to wealth through the ability to work more and later into life (Smith 1999). Indeed, Table 4 indicated a strong relationship between three health problems - sensory impairment, functional limitation, and disability - and the probability of working in the past year. In addition, bivariate analyses (not shown) indicated that healthier individuals are more likely to report having worked in the past year. But there are also some caveats to this viewpoint. First, Table 3 showed a relatively weak association between work and wealth, hence the indirect association leading from health to wealth may not be very strong. Second, the wealth measure used here is based on the household rather than the individual, and it is not clear to what extent older adults themselves contribute to household wealth regardless of their work status. Third, wealth, being a long-term indicator, may better relate to lifetime work status rather than status over the past year; the latter, however, is the only measure available in the current dataset.

Inasmuch as the association runs in the other direction, from wealth to health, it is quite possible that various psychosocial and psychobiological factors intervene. In the developed world, factors such as behavior, stress, access to health services, locus of control, and social support have been found to mediate the association between socioeconomic status and health, suggesting that a principal way to equalize health outcomes would be to alter associations 
between status and these intervening mechanisms (House et al. 1994; Kristenson et al. 2004; Kunz-Ebrecht, Krischbaum, and Steptoe 2004; Link and Phelan 1995; Siegrist and Marmot 2004; Williams 1990). Link and Phelan (1995) provided a notable addition to the psychosocial literature by suggesting that socioeconomic status is a fundamental cause of health, owing to the basic nature of the association between status and access to resources that exists across societies. This notion implies that the link between socioeconomic status and health should be robust across different countries, cultures, and environments even if the specific factors responsible for the association change. One might conjecture that since much of old-age existence is dependent upon family in rural Cambodia, social support and related factors of exchange may be the key intervening factors. Thus, connections may run through factors such as household size, intergenerational exchange, and quality and frequency of interactions. Associations in Table 3 showing that wealth is related to household size support this view. But there are also legitimate objections to this line of reasoning. For instance, Table 4 showed virtually no association between education and health, and one might expect that if psychosocial factors intervene, relationships would be found across socioeconomic measures. Also, Table 4 indicated little association between household size and health, calling into question an indirect association through indicators of support.

It was not anticipated that the association between wealth and disability would be weak and nonlinear. One possibility for this result, suggested earlier, is that disability and wealth are both related to a third factor, such as household size. That is, older adults tend to live with others when they require assistance in conducting daily tasks. In turn, larger households have greater wealth because an additional accumulation of assets is possible with each additional household member. If this explanation were correct, however, one would expect to see an association between household size and health, which was not the case in Table 4. A second possibility is that the U-shaped association with disability is partly a function of survival, which cannot be observed in a cross-sectional dataset. That is, those with disabilities in poor households may not live long, while those in wealthier households, owing to access to better health care and other types of support, might survive longer with their disabilities. In this case, the incidence of disability could be greater for those in lower wealth quartiles, whereas prevalence is greater for those in the higher quartiles.

Although differences in life expectancy across wealth quartiles likely play a role in determining prevalence rates of health problems, it is not clear why survival would have an impact on associations with disability but not on associations with other health outcomes. It is likely that the measure of disability differs in some way from the measure of other health problems. For instance, there may be reporting differences across wealth quartiles. Unlike sensory impairment and health symptoms, which are more or less objective, the ability to conduct activities of daily living is a function of environment and social and personal expectations (Freedman and Martin 1998; Verbrugge and Jette 1994). Even functional limitations are subject to variation across environments and expectations. Thus, the elderly in higher wealth quartiles may expect to enjoy better health and therefore perceive their health problems differently from those in lower quartiles. And those in higher quartiles may be required to conduct more difficult tasks, such as climbing stairs in a more modern residence or using modern bathing facilities, which results in greater inability to complete the task. 
In sum, the current study was limited both in its ability to test causal direction and in the number and types of variables considered for explanatory purposes. Nonetheless, it demonstrated a differentiation in health status among the very poorest of the poor. In a sense, those having next to nothing were shown to have better health than those having nothing. This suggests the possibility of generalizing the association between economic well-being and health to populations living in extreme poverty. 


\section{REFERENCES}

Annear, Peter. 1998. "Health and development in Cambodia." Asian Studies Review 22:193-221.

Anson, Ofra and Shifang Sun. 2003. "Health inequalities in rural China: Evidence from Hebei Province." Health and Place 10:75-84.

Antonovsky, Aaron. 1967. "Social class, life expectancy and overall mortality." Milbank Memorial Fund Quarterly 45:31-73.

Backlund, Eric, Paul D. Sorlie, and Norman J. Johnson. 1996. "The shape of the relationship between income and mortality in the United States: Evidence from the National Longitudinal Mortality Study." Annals of Epidemiology 6:1-9.

Berkman, Cathy S. and Barry J. Gurland. 1998. "The relationship among income, other socioeconomic indicators, and functional level in older persons." Journal of Aging and Health 10:81-98.

Beydoun, May A. and Barry M. Popkin. 2005. "The impact of socio-economic factors on functional status decline among community-dwelling older adults in China." Social Science and Medicine 60:2045-2057.

Bongaarts, John and Zachary Zimmer. 2002. "Living arrangements of the elderly in the developing world: An analysis of DHS household surveys." Journal of Gerontology: Social Sciences 57:S145-S157.

Chiu, H.C., Y.H. Hsieh, L.W. Mau, and M.L. Lee. 2005. "Associations between socio-economic status measures and functional change among older people in Taiwan." Ageing and Society 25:377-395.

Ecob, Russell and George Davey Smith. 1999. "Income and health: What is the nature of the relationship?" Social Science and Medicine 48:693-705.

Filmer, Deon and Lant H. Pritchett. 2001. "Estimating wealth effects without expenditure dataor tears: An application to educational enrollments in states of India." Demography 38:115-132.

Fox, John (ed). 1989. Health Inequalities in European Countries. Aldershot: Gower.

Freedman, Vicki A. and Linda G. Martin. 1998. "Understanding trends in functional limitations among older Americans." American Journal of Public Health 88:1457-1462.

Gornick, Marian E., Paul W. Eggers, Thomas Reilly, Renee M. Mentnech, Leslye K. Fitterman, Lawrence E. Kucken, and Bruce C. Vladeck. 1996. "Effects of race and income on 
mortality and use of services among Medicare beneficiaries." New England Journal of Medicine 335:791-799.

Grundy, Emily and Andy Sloggett. 2002. "Health inequalities in the older population: The role of personal capital, social resources and socio-economic circumstances." Social Science and Medicine 56:935-947.

Haan, Mary, George A. Kaplan, and Terry Camacho. 1987. "Poverty and health: Prospective evidence from the Alameda County Study." American Journal Epidemiology 125:989997.

Hermalin, Albert I., Mary Beth Ofstedal, and Shiauping R. Shih. 2003. "Patterns of intergenerational support in urban China and urban Taiwan." Pp. 255-275 in China's Revolutions and Intergenerational Relations, edited by Martin King Whyte. Ann Arbor: Center for Chinese Studies, University of Michigan.

Heuveline, Patrick. 1998. "'Between one and three million': Towards the demographic reconstruction of a decade of Cambodian history (1970-79)." Population Studies 52:4965.

Hobcraft, J.N., J.W. McDonald, and S.O. Rutstein. 1984. "Socio-economic factors in infant and child mortality: A cross-national comparison.” Population Studies 38:193-223.

House, James S., James M. Lepkowski, Ann M. Kinney, Richard P. Mero, Ronald C. Kessler, and Regula A. Herzog. 1994. "The social stratification of aging and health." Journal of Health and Social Behavior 38:213-234.

Houweling, T., A.E. Kunst, C. Looman, and J.P. Mackenbach. 2005. "Determinants of under-5 mortality among the poor and the rich: A cross-national analysis of 43 developing countries." International Journal of Epidemiology 34:1257-1265.

Huisman, Martijn, Anton E. Kunst, and Johan P. Mackenbach. 2003. "Socioeconomic inequalities in morbidity among the elderly: A European overview." Social Science and Medicine 57:861-873.

Kadushin, Charles. 1964. "Social class and the experience of ill health." Sociological Inquiry 34:67-80.

Kaneda, Toshiko, Zachary Zimmer, and Zhe Tang. 2005. "Socioeconomic status differentials in life and active life expectancy among older adults in Beijing." Disability and Rehabilitation 27:241-251.

Katz, S., A.B. Ford, R.W. Moskowitz, B.A. Jackson, and M.W. Jaffee. 1963. "Studies of illness in the aged: The index of ADL, a standardized measure of biological and psychosocial function." Journal of the American Medical Association 185:914-919. 
Kiernan, Ben. 1996. The Pol Pot Regime: Race, Power and Genocide in Cambodia Under the Khmer Rouge, 1975-1979. Chiang Mai: Silkworm.

Kitagawa, Evelyn M. and Philip M. Hauser. 1973. Differential Mortality in the United States: A Study of Socioeconomic Epidemiology. Cambridge: Harvard University Press.

Knodel, John, Kiry Sovan Kim, Zachary Zimmer, and Sina Puch. 2005. "Older persons in Cambodia: A profile from the 2004 Survey of Elderly." UNFPA Cambodia and Royal University of Phnom Penh.

Knodel, John, Zachary Zimmer, Kiry Sovan Kim, and Sina Puch. 2006. "The impact of AIDS on older-age parents in Cambodia." PSC Research Report No. 06-594. Ann Arbor, MI: Population Studies Center, University of Michigan.

Kristenson, M., H.R. Eriksen, J.K. Sluiter, D. Starke, and H. Ursin. 2004. "Psychobiological mechanisms of socioeconomic differences in health." Social Science and Medicine 58:1511-1522.

Kunz-Ebrecht, Sabine R., Clemens Kirschbaum, and Andrew Steptoe. 2004. "Work stress, socioeconomic status and neuroendocrine activation over the working day." Social Science and Medicine 58:1523-1530.

Liang, J., X. Liu, and S. Gu. 2001. "Transitions in functional status among older people in Wuhan, China: Socioeconomic differentials." Journal of Clinical Epidemiology 54:11261138 .

Liang, J., J.F. McCarthy, A. Jain, N. Krause, J.M. Bennett, and S. Gu. 2000. "Socioeconomic gradient in old age mortality in Wuhan, China." Journal of Gerontology: Social Sciences 55:222-233.

Link, Bruce G. and Jo Phelan. 1995. "Social conditions as fundamental causes of disease." Journal of Health and Social Behavior 36:80-94.

Lynch, John W., George A. Kaplan, and Sara J. Shema. 1997. "Cumulative impact of sustained economic hardship on physical, cognitive, psychological, and social functioning." New England Journal of Medicine. 337:1889-1895.

Mackenbach, Johan P., Anton E. Kunst, Adrienne E.J.M. Cavelaars, Feikje Groenhof, Jose J.M. Geurts, and EU Working Group on Socioeconomic Inequalities in Health. 1997. "Socioeconomic inequalities in morbidity and mortality in western Europe." The Lancet 349:1655-1659.

Martin, Linda G. 1988. "The aging of Asia.” Journal of Gerontology 43:99-113. 
Matthews, Ruth J., Carol Jagger, and Ruth M. Hancock. 2006. "Does socio-economic advantage lead to a longer, healthier old age?" Social Science and Medicine 62:2489-2499.

Mayhew, Leslie. 1999. "Health and welfare services expenditure in an aging world." Interim Report \# IR-99-035. Laxenburg, Austria: International Institute for Applied Systems Analysis.

McDonough, Peggy, Greg J. Duncan, David R. Williams, and James S. House. 1997. "Income dynamics and adult mortality in the United States, 1972 through 1989." American Journal of Public Health 87:1476-1483.

Menchik, Paul L. 1983. "Economic status as a determinant of mortality among nonwhite and white older males: Or, does poverty kill?” Population Studies 47:427-436.

Ministry of Planning. 2003. Cambodia Millennium Development Goals Report 2003. Phnom Penh: Ministry of Planning, Royal Government of Cambodia.

Montgomery, Mark R. and Paul C. Hewett. 2005. "Urban poverty and health in developing countries: Household and neighborhood effects." Demography 42:397-425.

Nagi, Saad Z. 1979. "The concept and measurement of disability.” Pp. 1-15 in Disability Policies and Government Programs, edited by E. D. Berkowitz. New York, NY: Praeger.

National Research Council. 2001. Preparing for an Aging World: The Case for Cross-National Research. Washington, DC: National Academy Press.

Population Reference Bureau. 2005. 2005 World Population Data Sheet. Washington, D.C.: Population Reference Bureau.

Robert, Stephanie and James S. House. 1996. "SES differentials in health by age and alternative indicators of SES." Journal of Aging and Health 8:359-388.

Rutstein, Shea and Kiersten Johnson. 2004. The DHS Wealth Index. Calverton, MD: ORC Macro.

Siegrist, Johannes and Michael Marmot. 2004. "Health inequalities and the psychosocial environment: Two scientific challenges.” Social Science and Medicine 58:1463-1473.

Smith, James P. 1999. "Healthy bodies and thick wallets: The dual relation between health and economic status." Journal of Economic Perspectives 13:145-166.

Sorlie, P.D., E. Backlund, and J. Keller. 1995. "Mortality by economic, demographic, and social characteristics - The National Longitudinal Mortality Study." American Journal of Public Health 85:949-956. 
Verbrugge, Lois M. and Alan M. Jette. 1994. "The disablement process." Social Science and Medicine 38:1-14.

von dem Knesebeck, Olaf, Gunther Luschen, William C. Cockerham, and Johannes Siegrist. 2003. "Socioeconomic status and health among the aged in the United States and Germany: A comparative cross-sectional study." Social Science and Medicine 57:16431652.

Wilkinson, R.G. 1986. "Income and mortality." Pp. 88-114 in Class and Health: Research and Longitudinal Data, edited by R. G. Wilkinson. London: Tavistock Publications.

Williams, David R. 1990. "Socioeconomic differentials in health: A review and redirection." Social Psychology Quarterly 53:81-99

World Health Organization. 1980. International Classification of Impairments, Disabilities and Handicaps. Geneva: World Health Organization.

Zeng, Yi, James W. Vaupel, Xiao Zhenyu, Zhang Chunyuan, and Liu Yuzhi. 2001. "The Healthy Longevity Survey and the active life expectancy of the oldest old in China." Population: An English Selection 13: 95-116.

Zimmer, Zachary. 2006a. "Disability and active life expectancy among older Cambodians." Asian Population Studies 2: 133-148.

—. 2006b. "Population aging." Pp. 936-940 in Encyclopedia of Gerontology, edited by R. Schulz, L. S. Noelker, K. Rockwood, and R. L. Sprott. New York, NY: Springer.

Zimmer, Zachary and Pattama Amornsirisomboon. 2001. "Socioeconomic status and health among older adults in Thailand: An examination using multiple indicators." Social Science and Medicine 52:1297-1311.

Zimmer, Zachary, Napaporn Chayovan, Hui-Sheng Lin, and Josefina Natividad. 2004. "How indicators of socioeconomic status relate to physical functioning of older adults in three Asian societies." Research on Aging 26:224-258.

Zimmer, Zachary and James S. House. 2003. "Education, income and functional limitation transitions among American adults: Contrasting onset and progression." International Journal of Epidemiology 32:1089-1097.

Zimmer, Zachary, John Knodel, Kiry Sovan Kim, and Sina Puch. 2006. "The impact of past conflicts and social disruption on the elderly in Cambodia." Population and Development Review 32:333-360.

Zimmer, Zachary and Julia Kwong. 2004. "Socioeconomic status and health among older adults in rural and urban China." Journal of Aging and Health 16:44-70. 
Table 1 Descriptive information for sample showing percent distributions by sex

\begin{tabular}{|c|c|c|c|c|}
\hline & $\begin{array}{l}\text { Total } \\
(\mathrm{N}=1,011)\end{array}$ & $\begin{array}{l}\text { Men } \\
(\mathrm{N}=416)\end{array}$ & $\begin{array}{l}\text { Women } \\
(\mathrm{N}=595)\end{array}$ & P-Value ${ }^{a}$ \\
\hline \multicolumn{5}{|l|}{ Age } \\
\hline $60-64$ & 31.9 & 32.5 & 31.5 & .61 \\
\hline $65-69$ & 26.6 & 28.4 & 25.3 & \\
\hline $70-74$ & 21.4 & 20.2 & 22.3 & \\
\hline $75+$ & 20.1 & 19.0 & 20.8 & \\
\hline \multicolumn{5}{|l|}{ Marital status } \\
\hline Married & 51.8 & 81.0 & 31.4 & .00 \\
\hline Widowed & 44.4 & 16.3 & 63.0 & \\
\hline Separated/divorced & 2.9 & 2.6 & 3.0 & \\
\hline Never married & 0.9 & 0.0 & 1.5 & \\
\hline \multicolumn{5}{|l|}{ Ethnicity } \\
\hline Khmer $^{\mathrm{b}}$ & 89.5 & 89.9 & 89.3 & .88 \\
\hline \multicolumn{5}{|l|}{ Religion } \\
\hline Buddhist $^{\mathrm{c}}$ & 95.1 & 94.2 & 95.8 & .21 \\
\hline \multicolumn{5}{|l|}{ Schooling } \\
\hline None & 58.2 & 25.5 & 81.0 & .00 \\
\hline Primary/pagoda & 34.6 & 60.7 & 16.3 & \\
\hline More than primary & 7.2 & 13.7 & 2.7 & \\
\hline \multicolumn{5}{|l|}{ Labor force participation } \\
\hline Worked within last year & 38.2 & 49.6 & 30.3 & .00 \\
\hline \multicolumn{5}{|l|}{ Occupation most of life } \\
\hline Agriculture & 78.4 & 80.7 & 76.8 & .00 \\
\hline Other & 18.2 & 19.3 & 17.5 & \\
\hline Never worked & 3.4 & 0.0 & 5.7 & \\
\hline \multicolumn{5}{|l|}{ Living arrangement } \\
\hline Lives with at least one offspring & 78.7 & 83.9 & 75.1 & .00 \\
\hline \multicolumn{5}{|l|}{ Household size } \\
\hline 1 & 3.6 & 1.0 & 5.4 & .00 \\
\hline 2 & 10.7 & 8.9 & 11.9 & \\
\hline 3 to 5 & 39.9 & 45.2 & 36.1 & \\
\hline $6+$ & 45.9 & 45.0 & 46.6 & \\
\hline
\end{tabular}

${ }^{\mathrm{a}}$ Tests distributions of men versus women using $\chi^{2}$.

${ }^{\mathrm{b}}$ Others include Cham, Chinese, and Vietnamese.

'Others include Christian, Islam, and unstated. 
Table 2 Percent reporting health problems by age and sex

\begin{tabular}{|c|c|c|c|c|c|}
\hline & $\mathrm{N}$ & $\begin{array}{l}\text { Six or more } \\
\text { health } \\
\text { symptoms }\end{array}$ & $\begin{array}{l}\text { One or both } \\
\text { sensory } \\
\text { impairments }\end{array}$ & $\begin{array}{l}\text { One or more } \\
\text { functional } \\
\text { limitations }\end{array}$ & $\begin{array}{l}\text { One or more } \\
\text { disabilities }^{\mathrm{d}}\end{array}$ \\
\hline \multicolumn{6}{|l|}{ Age } \\
\hline 60 to 64 & 346 & 51.1 & 56.0 & 33.1 & 12.1 \\
\hline 65 to 69 & 258 & 54.5 & 69.9 & 46.1 & 22.0 \\
\hline 70 to 74 & 206 & 62.7 & 78.3 & 66.7 & 31.5 \\
\hline $75+$ & 201 & 63.5 & 83.7 & 82.3 & 36.0 \\
\hline P-value & & .00 & .00 & .00 & .00 \\
\hline \multicolumn{6}{|l|}{ Sex } \\
\hline Men & 416 & 52.5 & 70.4 & 39.0 & 20.0 \\
\hline Women & 595 & 60.0 & 69.9 & 63.9 & 26.4 \\
\hline P-value & & .02 & .86 & .00 & .02 \\
\hline Total sample & 1,011 & 57.0 & 70.1 & 53.6 & 23.7 \\
\hline
\end{tabular}

${ }^{a}$ Has experienced six or more of the following symptoms within the last month: joint pain, dizziness, headaches, fever, chest pain, coughing, trembling hands, stomach ache, breathing problems, diarrhea, skin problems, vomiting.

${ }^{b}$ Has difficulty seeing without glasses and/or hearing without a hearing aid.

${ }^{\mathrm{c}} \mathrm{Has}$ a lot of difficulty or cannot walk, climb stairs, grasp with fingers, lift, crouch.

${ }^{\mathrm{d}}$ Has any difficulty eating, dressing, bathing, getting up from bed.

${ }^{\mathrm{e}}$ Tests distributions across age categories or sex using $\chi^{2}$. 
Table 3 Number of assets, percent of households owning specific assets, and selected demographic characteristics, by wealth quartiles

\begin{tabular}{lllllll}
\hline & & \multicolumn{2}{c}{ Quartile } & & & \\
\cline { 5 - 7 } & Total & & & & & \\
Sample & Lowest & Second & Third & Highest & P- \\
& $(\mathrm{N}=1,011)$ & $(\mathrm{N}=289)$ & $(\mathrm{N}=263)$ & $(\mathrm{N}=238)$ & $(\mathrm{N}=221)$ & Value $^{\mathrm{a}}$ \\
\hline
\end{tabular}

$\begin{array}{lllllll}\text { A. Statistics about number of assets owned } & & & & & \\ \text { Mean } & 2.44 & 0.45 & 1.58 & 2.88 & 5.57 & .00 \\ \text { Standard deviation } & 2.08 & 0.50 & 0.49 & 0.67 & 1.60 & \\ \text { Median } & 2 & 0 & 2 & 3 & 5 \\ 10^{\text {th }} \text { percentile } & 0 & 0 & 1 & 2 & 4 & \\ 90^{\text {th }} \text { percentile } & 5 & 1 & 2 & 4 & 8\end{array}$

\begin{tabular}{|c|c|c|c|c|c|c|}
\hline \multicolumn{7}{|c|}{ B. Percent of households owning asset } \\
\hline Radio & 67.4 & 44.6 & 58.6 & 81.5 & 92.3 & .00 \\
\hline Television & 60.6 & 0 & 81.0 & 78.9 & 95.9 & .00 \\
\hline Modern toilet & 27.4 & 0 & 1.9 & 37.8 & 82.4 & .00 \\
\hline Jewelry & 25.6 & 0 & 14.1 & 44.5 & 52.5 & .00 \\
\hline Motorcycle & 25.1 & 0 & 2.3 & 32.9 & 76.9 & .00 \\
\hline Modern floor & 12.3 & 0 & 0.8 & 9.7 & 44.8 & .00 \\
\hline Telephone & 10.7 & 0 & 0 & 1.7 & 47.1 & .00 \\
\hline Fan & 10.6 & 0 & 0 & 0.4 & 48.0 & .00 \\
\hline Car & 2.5 & 0 & 0 & 0.8 & 10.4 & .00 \\
\hline Refrigerator & 1.7 & 0 & 0 & 0 & 7.7 & .00 \\
\hline \multicolumn{7}{|c|}{ C. Demographic characteristics } \\
\hline Percent female & 58.9 & 63.3 & 57.8 & 51.7 & 62.0 & .04 \\
\hline Percent married & 51.8 & 50.9 & 50.8 & 41.2 & 49.3 & .10 \\
\hline Percent with schooling & 41.7 & 34.4 & 36.9 & 49.6 & 48.6 & .00 \\
\hline $\begin{array}{l}\text { Percent working in last } \\
\text { year }\end{array}$ & 61.8 & 58.5 & 59.7 & 58.4 & 72.4 & .00 \\
\hline $\begin{array}{l}\text { Percent in agriculture } \\
\text { most of life }\end{array}$ & 78.4 & 86.9 & 84.1 & 79.3 & 59.7 & .00 \\
\hline Percent living with a child & 78.6 & 65.1 & 76.4 & 87.0 & 90.0 & .00 \\
\hline Mean household size & 5.4 & 4.2 & 5.5 & 5.7 & 6.4 & .00 \\
\hline
\end{tabular}


Table 4 Logistic regression results for health measures showing odds ratios

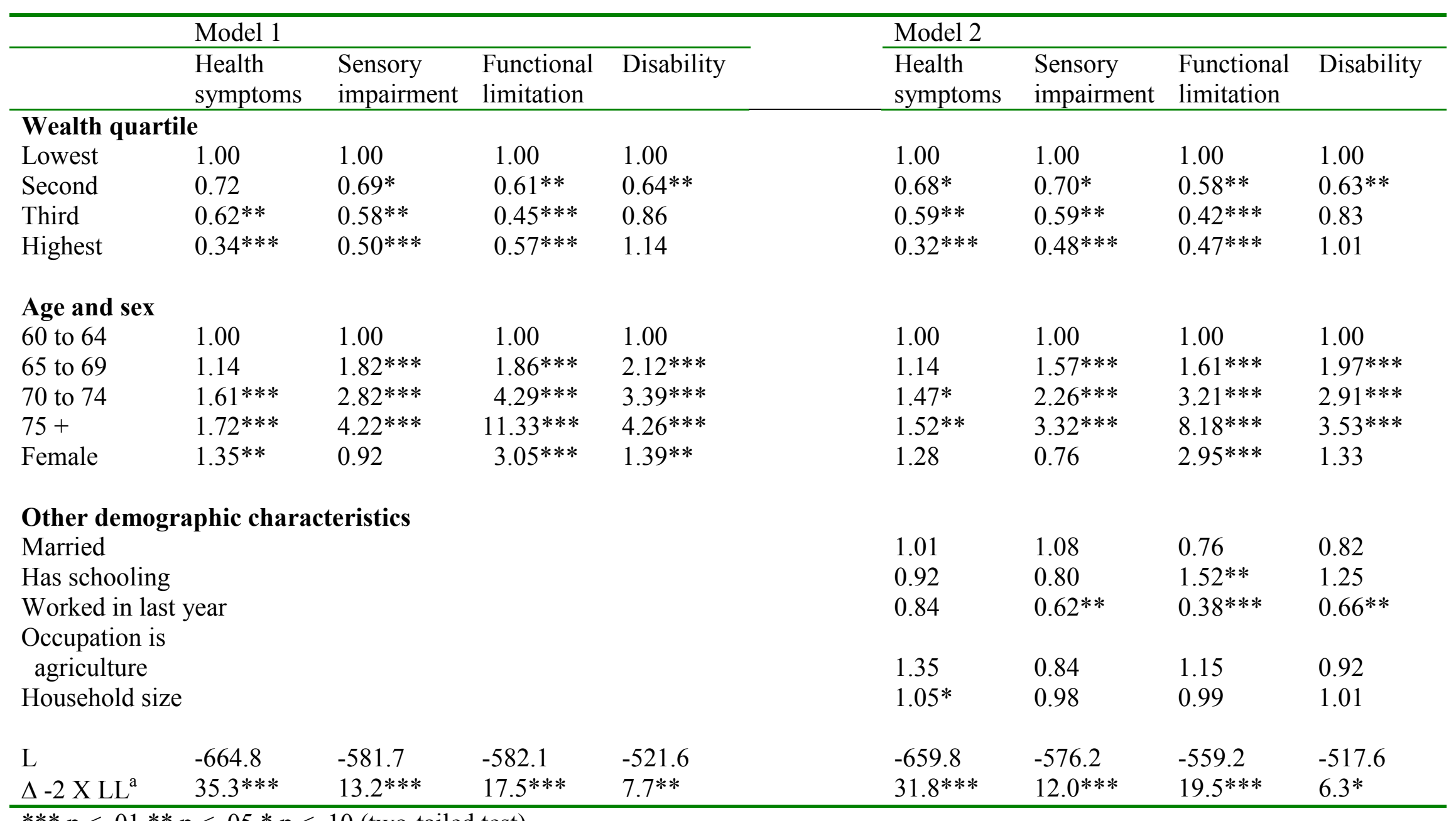

$* * * \mathrm{p}<.01 * * \mathrm{p}<.05 * \mathrm{p}<.10$ (two-tailed test)

${ }^{a}$ Change in $-2 \mathrm{X}$ log-likelihood when adding wealth quartiles to a model containing other variables 
Figure 1 Predicted probability of reporting health problems by wealth quartile

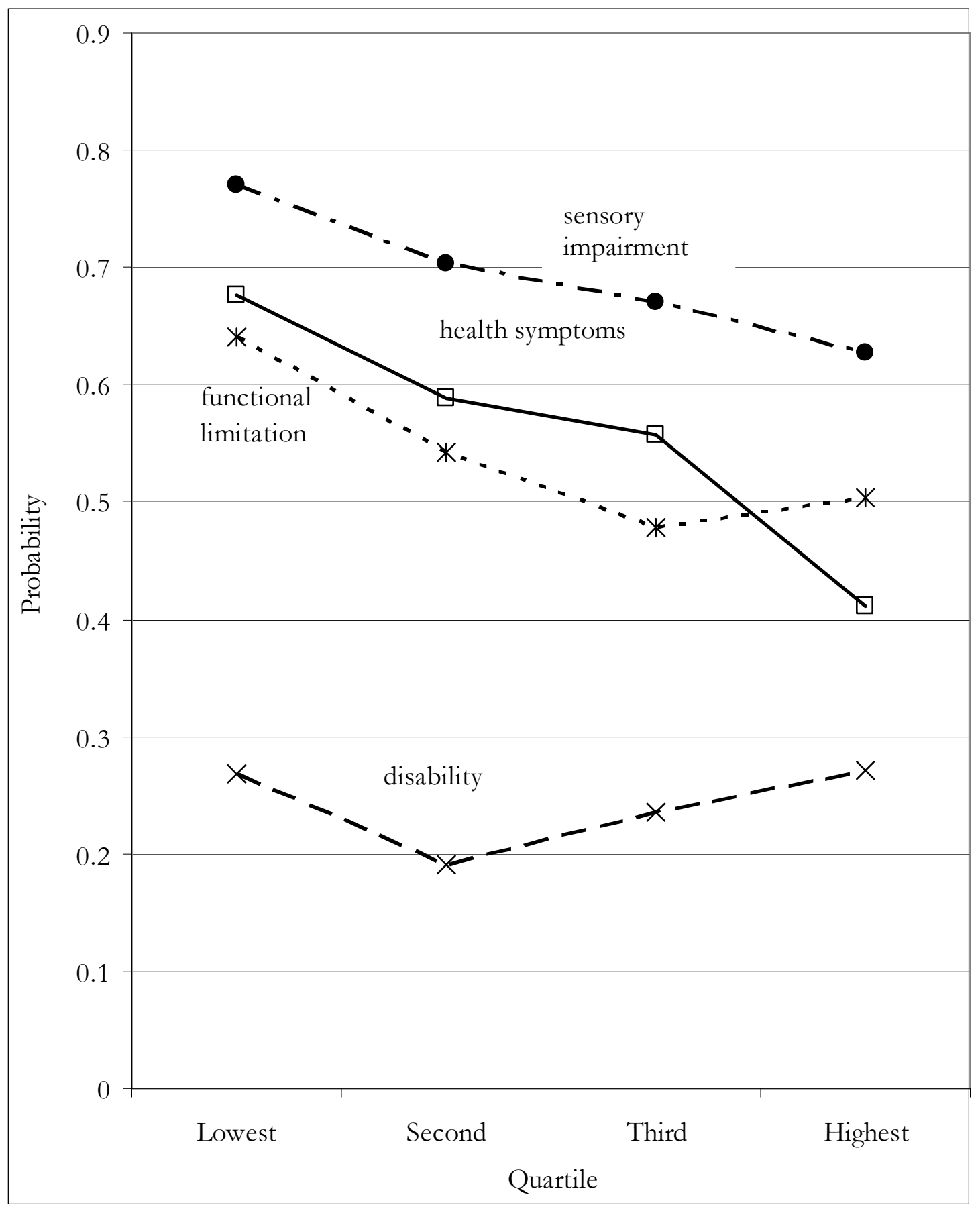

${ }^{a}$ Adjusts for age, sex, marital status, schooling, work status, agricultural occupation, and household size 


\section{POLICY RESEARCH DIVISION WORKING PAPERS}

If still in print, single copies of up to three working papers from 1989 through 2003 are available free of charge.

Beginning with the 2004 issues, working papers are no longer available in print format. Instead they are distributed electronically. As each new paper is completed subscribers are notified by e-mail and a link to the paper is provided.

To subscribe to the Policy Research Division working paper e-mail notification list, or to obtain back issues from 1989 to 2003, please send your request to prdwp@popcouncil.org. PDFs of recent issues are available at www.popcouncil.org/publications/wp/prd/rdwplist.html

2006

217 Zachary Zimmer, "Poverty, wealth inequality, and health among older adults in rural Cambodia."

216 John Bongaarts, "Late marriage and the HIV epidemic in subSaharan Africa."

215 John Bongaarts, "How long will we live?"

214 Zachary Zimmer, Toshiko Kaneda, and Laura Spess, "Urban versus rural mortality among older adults in China."

213 Paul Demeny and Geoffrey McNicoll, "The political demography of the world system, 2000-2050."

212 Monica Grant and Kelly Hallman, "Pregnancy-related school dropout and prior school performance in South Africa."
211 Kelly Hallman, Sara Peracca, Jennifer Catino, and Marta Julia Ruiz, "Multiple disadvantages of Mayan females: The effect of gender, ethnicity, poverty, and residence on education in Guatemala."

210 Geoffrey McNicoll, "Policy lessons of the East Asian demographic transition."

209 Cynthia B. Lloyd, Cem Mete, and Monica J. Grant, "The implications of changing educational and family circumstances for children's grade progression in rural Pakistan: 1997-2004."

2005

208 James F. Phillips, Ayaga A. Bawah, and Fred N. Binka, "Accelerating reproductive and child health program development:

The Navrongo Initiative in Ghana."

207 John Bongaarts and Griffith Feeney, "The quantum and tempo of life-cycle events." 
206 Barbara S. Mensch, Monica J. Grant, and Ann K. Blanc, "The changing context of sexual initiation in sub-Saharan Africa."

205 Geoffrey McNicoll, "Population and sustainability."

204 John Bongaarts, "The causes of stalling fertility transitions."

203 Ayaga A. Bawah and Fred N. Binka, "How many years of life could be saved if malaria were eliminated from a hyperendemic area of northern Ghana?"

202 Barbara S. Mensch, Susheela Singh, and John B. Casterline, "Trends in the timing of first marriage among men and women in the developing world."

201 Zachary Zimmer, "Active life expectancy and functional limitations among older Cambodians: Results from a 2004 survey."

200 Brian Wells Pence, Philomena Nyarko, James F. Phillips, and Cornelius Debpuur, "The effect of community nurses and health volunteers on child mortality: The Navrongo Community Health and Family Planning Project."

199 Zachary Zimmer, Linda G. Martin, Mary Beth Ofstedal, and Yi-Li Chuang, "Education of adult children and mortality of their elderly parents in Taiwan."

198 Mian Bazle Hossain, James F. Phillips, and Thomas K. LeGrand, "The impact of childhood mortality on fertility in six rural thanas of Bangladesh."
197 Kristine R. Baker, Mary Beth Ofstedal, Zachary Zimmer, Zhe Tang, and Yi-Li Chuang, "Reciprocal effects of health and economic well-being among older adults in Taiwan and Beijing."

196 Mark R. Montgomery and Paul C. Hewett, "Poverty and children's schooling in urban and rural Senegal." 
195 Luciana Suran, Sajeda Amin, Lopita Huq, and Kobita Chowdury, "Does dowry improve life for brides? A test of the bequest theory of dowry in rural Bangadesh."

194 Barbara S. Mensch, Monica J. Grant, Mary P. Sebastian, Paul C. Hewett, and Dale Huntington. "The effect of a livelihoods intervention in an urban slum in India: Do vocational counseling and training alter the attitudes and behavior of adolescent girls?"

193 Amanda Ritchie, Cynthia B. Lloyd, and Monica Grant. "Gender differences in time use among adolescents in developing countries: Implications of rising school enrollment rates."

192 John Bongaarts. "Long-range trends in adult mortality: Models and projection methods."

191 John Koku Awoonor-Williams, Ellie S. Feinglass, Rachel Tobey, Maya N. Vaughan-Smith, Frank K. Nyonator, Tanya C. Jones, and James F. Phillips, "Bridging the gap between evidence-based innovation and national healthsector reform in Ghana."

190 Kelly Hallman, "Socioeconomic disadvantage and unsafe sexual behaviors among young women and men in South Africa."

189 Toshiko Kaneda, Zachary Zimmer, and Zhe Tang, "Differentials in life expectancy and active life expectancy by socioeconomic status among older adults in Beijing."
188 Cynthia B. Lloyd and Monica J. Grant, "Growing up in Pakistan: The separate experiences of males and females."

187 Zachary Zimmer, Xianghua Fang, Toshiko Kaneda, Zhe Tang, and Julia Kwong. "Trends and transitions in children's coresidence with older adults in Beijing municipality."

186 Sajeda Amin and Alaka M. Basu. "Popular perceptions of emerging influences on mortality and longevity in Bangladesh and West Bengal."

185 John Bongaarts. "Population aging and the rising cost of public pensions."

184 Mark R. Montgomery and Paul C. Hewett. "Urban poverty and health in developing countries: Household and neighborhood effects." 